\title{
The iconography of vehicle automation-a focus group study
}

\author{
Joy Richardson ${ }^{1}$ (1) $\cdot$ Kirsten M. A. Revell $^{1}$ Jisun $\mathrm{Kim}^{1} \cdot$ Neville A. Stanton ${ }^{1}$
}

Received: 2 April 2020 / Accepted: 10 June 2021

(c) The Author(s) 2021

\begin{abstract}
SAE level 2 and 3 semi-autonomous vehicles are widely available but, due to the nature of automation, their in-vehicle displays are required to communicate more complex information to the driver. Examination of interfaces from a variety of manufacturers revealed a clear lack of consistency in the way key information is displayed. Different manufacturers have adopted icons varying in shape and colour to convey the same message. When driving a semi-autonomous vehicle, mode awareness is critical for trust, performance and safety. Standardisation of icons has been shown to have many benefits including opening products up to wider international markets by helping overcome language and cultural barriers, by providing a method of communication which can surpass them. However, the current lack of standardisation in icon design could cause mode confusion and has little cross-vehicle compatibility. To understand the impact of mode confusion on users, a focus group was held in which participants were asked to interpret the meaning of icons from a variety of different driver interfaces. Ambiguity in user interpretations makes the case for the introduction of new ISO standard icons to better support drivers in SAE level 2 and 3 automated vehicles.
\end{abstract}

Keywords Semi-autonomous $\cdot$ Automobile $\cdot$ Interface design $\cdot$ Icons

\section{Introduction}

As partially automated (SAE level 2), vehicles have been available for several years and conditionally automated (SAE level 3) vehicles are currently in production (Gasser and Westhoff 2012; Kim, et al. 2020a, b; SAE 2018) dashboard displays are becoming more sophisticated and required to communicate more complex information (Locken et al. 2020; You et al. 202). This automation is formed from combining a system of longitudinal control (such as adaptive cruise control (ACC)) providing brake and throttle input with system(s) of lateral control (such as following lanes or a lead vehicle) providing steering. It is essential that the driver is aware of the mode of the vehicle in order to remain safe and this is most commonly communicated on the dashboard or other in-vehicle display pictorially (Stanton et al. 2011).

Joy Richardson

jr1d11@soton.ac.uk

1 Human Factors Engineering, Transportation Research Group, Boldrewood Innovation Campus, University of Southampton, Burgess Road, Southampton SO16 7QF, UK
The use of pictures to convey meaning is one of the oldest forms of communication; prior to the invention of written languages, these pictures would be used to record history and tell stories (Horton 1994; Moser 1998; Greenberg 2013). As shown in Fig. 1, icons are a way of using pictures to deliver a specific message and are formed of several elements which can include a border, a background and text but is focused on the pictorial element, known as the symbol (Carney et al. 1998). Studies have shown that well-designed icons can be recognised more quickly and accurately than textual displays, (Horton 1994; Carney, Campbell and Mitchell 1998; Green 1993; Baber and Wankling 1992). They also have the benefit of consuming less space than text, of particular importance on the small and busy real estate of a screen (Green 1993; Baber and Wankling 1992) and, if well designed, can be universally understood and language independent (McDougall et al. 2000; Chanwimalueng and Rapeepisarn 2013; Zwaga and Mijksenaar 2000; Buhler et al. 2020).

Carney et al. (1998) proposed that icons can be classified into three types: pictorial representations of the object or action they represent with meaning easily derived and little effort required to learn; concept-related icons based on an image or a property of an actual object or action, these can 


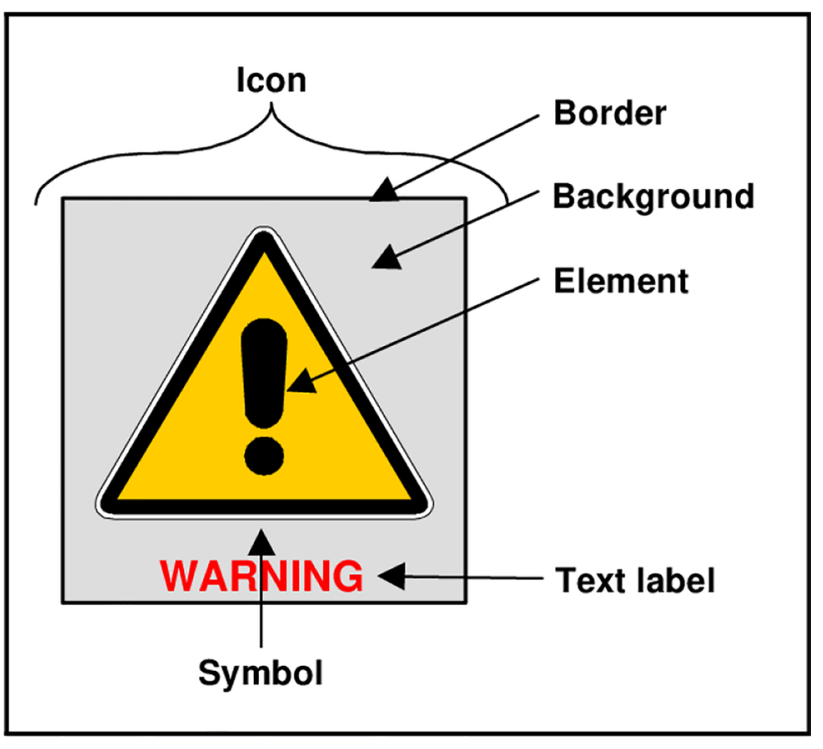

Fig. 1 Composition of an icon (Carney et al 1998)

be context specific so are more difficult to learn; and arbitrary icons which are only meaningful through convention and rely on particular knowledge, which can be cultural. The latter of these are the most difficult type of icon to learn. $\mathrm{Yu}$ (2018) proposes a similar system with the concept of the image icon which have similarities to real world items, the referential icon which has a simply understood association and the symbolic icon which does not have an obvious relation to what it represents where understanding is due to culture and tradition. Others have categorised types of icon as abstract or concrete (Lin 1994) or consider abstract and concrete as opposite ends of a scale (McDougall et al. 2000). However, all agree that the easiest to understand are those which closest represent real items, as the visual metaphor is clear without the need for prior learning or experience (Carney, Campbell and Mitchell 1998; Lin 1994; McDougall et al. 2000; Shen et al 2018).

Previous studies, evaluating the automation systems and human machine interfaces across a range of SAE level 2 vehicles, identified some mode confusion whereby the driver has been unsure of whether they are in control of the vehicle or if it is automated, despite the mode being displayed on the vehicle's dashboard (Stanton et al. 2011; Revell, et al. 2018; Kim, et al. 2020a, b). During these studies across different vehicles, it was observed that the icon indicating the activation or deactivation of automated modes could be green, white or blue, but the icon remained a pictorial image of a steering wheel. It is clear from examining the interfaces from different manufacturers that the levels of functionality are being interpreted very differently. It is possible this could be due to the lack of standardisation in associated displays and imagery.
The International Organisation for Standardisation (ISO) is an independent non-governmental organisation whose responsibility it is to make international standards. They have a voluntary membership of 162 standard bodies worldwide and create standards across a wide range of sectors, from agriculture and healthcare, to transport (ISO 2014, 2016). ISO standardised signs (small icons) and symbols (larger images), both of which will be referred to as icons in this paper, have been commonly used to communicate messages to automobile drivers on the vehicle dashboard for many years, and the ISO aim to maximise the potential of icons through worldwide standardisation (Zwaga and Mijksenaar 2000). This can be seen to originate with the standardisation of traffic light colours in the 1920s (Priest et al. 2005), which are reflected in the use of those same colours on the dashboard, through to the development of icon recommendations in the 1970s (Green 1993; Saunby et al. 1988). Due to new technologies, these icons are now also being displayed on additional screens within the vehicle, commonly located in the centre of the vehicle or as a head-up display. These combined screens are known as invehicle information systems (IVIS) and whilst they may also provide entertainment, comfort and navigation (Harvey and Stanton 2013), an additional purpose is to provide information to the driver in order to increase safety during driving, thus protecting road users and reducing costs associated with accidents, collision and congestion (Carney, Campbell and Mitchell 1998, Meixner et al 2000). ISO 2575 outlines all the standardised icons in use and is revised every 5 years (ISO 2017); it also forms the basis for British Standard BS ISO 2575 (BSI 2010). Currently, there are over 300 of these standards falling into 18 categories, from lighting and signalling to vehicle handling. The basic shape and colours of these icons are standardised, which is important in helping ensure the messages they convey are recognised and understood (ISO 2013). These standardised icons are designed to assist the driver in interpreting dashboard messages, even when driving an unfamiliar vehicle.

Within ISO standard 2575, icons supporting the communication of aspects of automated driving are few. Section $\mathrm{J}$ relates to vehicle handling and cruise control and covers icons for such capabilities including parking assist and hill descent control. The section contains icon J.09 to indicate when ACC is active, this system accelerates or decelerates a vehicle to maintain a set speed and distance to the vehicle in front, and forms the basis for many of the more advanced automated driving systems available in SAE level 2 vehicles. Icon J.10 indicates if the ACC system has failed (see Fig. 2). However, there are a number of key characteristics related to automated driving which are absent. In March 2018, a draft for the new version of the standard was released to the public for comments and is due for publication shortly. This draft does not contain any additional icons to support 
Fig. 2 Icons relating to ACC (ISO 2010)

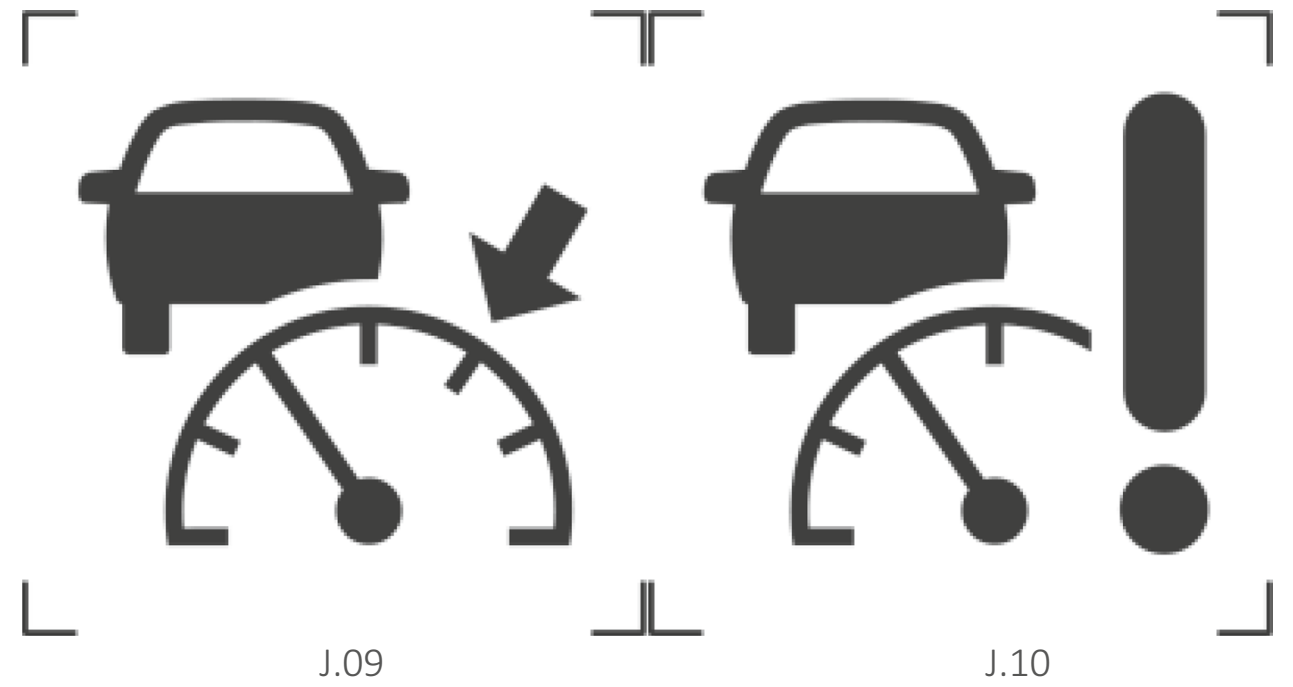

automated driving (BSI 2018). There is an additional, more recent, draft resolution which has recently been circulated to ISO international committee stakeholders which does look at introducing icons which could be used to indicate modes in SAE level 2 vehicles.

In addition to prescribing the shape of icons, the ISO standard 2575 also states how colours should be used as they have the following meanings attached. Importantly, an icon may be shown in more than one colour to convey a change in operation of that system (ISO 2010).

- Red-immediate or imminent danger to persons or equipment.

- Yellow/amber-caution, malfunction, damage likely or potential hazard.

- Green-safe, normal operation.

- Blue-only used in relation to headlights (main beam or high beam).

- White-may be used when no other condition applies.

Benefits of standardisation have been shown to include opening products up to wider international markets by helping overcome language and cultural barriers, providing a method of communication which can surpass them (ISO 2013, 2014; Stuart-Buttle 2006; Green 1993; Buhler et al. 2020) Chong et al. 1990). They can improve the image of the original equipment manufacturers and reduce exposure to liability from new technologies (Priest, Wilson and Salas 2005). Most importantly, standards can increase safety (Sherehiy, Karwowski and Rodrick 2006; Priest, Wilson and Salas 2005; ISO 2014) which, in the context of driving, can save lives. Road traffic collisions are the eighth most common cause of death (World Health Organization 2018), accounting for 1.25 million deaths per year worldwide (Gorea 2016) and 1793 deaths in 2017 in Great Britain
(Department for Transport 2018). Since their initiation in 1968, the US safety standards are thought to have saved the lives of thousands of road users (Priest, Wilson and Salas 2005). This is due to standardisation making systems more understandable (Priest, Wilson and Salas 2005), thereby reducing confusion and failure (Horton 1994). Equally, the impact of the lack of standardisation in IVIS icons has led to poor design, including the use of multiple different icons across manufacturers, which are attempting to communicate the same message (Carney, Campbell and Mitchell 1998). This combination of divergence and underdeveloped design can cause confusion or distraction (Horton 1994; Baber and Wankling 1992; Stanton et al. 2011). Whereas if standardisation is not well designed, it can be poorly received in some cultures, and therefore, multi-cultural compatibility must also be a consideration (Goonerilleke et al 2001; Khan et al. 2016; Buhler et al. 2020). Poorly designed icons make a system more difficult to use (Horton 1994), increasing workload, errors and stress (Priest, Wilson and Salas 2005; Walker et al 2017; Walch et al. 2020), all of which can increase the likelihood of confusion and therefore of being involved in a road traffic accident by delaying or creating an incorrect input from the driver (Frank et al. 1973).

Human factors methods have been used to help design icons (Campbell 2016). Green (1981) and Chong et al. (1990) both used design workshops with members of the public designing icons for used in IVIS. In both cases, the participants were asked to hand draw their own ideas for a variety of alerts such as oil level, coolant pressure and a variety of cruise control functions. Whilst these icons may have lacked in aesthetics and legibility, both studies had similar conclusions, agreeing that the ideas created by the end user were a good point from which to develop candidate icons for future testing, and had the benefit of being quite different from that which would have been developed by designers. In 
addition to these design methods, the ISO have produced test 9186, Part 1: Method for Testing Comprehensibility (BSI 2014). This has been developed due to the increasing volume of information related via icons to the public, in order to ensure that only one symbol is used internationally to convey each meaning. The test can be used to quantify the comprehensibility of an icon across a representative sample of the end user population, to include those of different age, sex, education level, cultural or ethnic background and physical ability. When associated with an icon to be used internationally, it requires participants from a minimum of three countries, preferably from different cultural backgrounds. The participants are shown an image of the icon with a short description of where it could be found and then asked two questions: (1) What do you think the symbol means? and (2) What action should you take in response to this symbol? The results are then classified as:

- 1-correct,

- 2-wrong,

- $2 \mathrm{a}$-wrong and response is the opposite of the intended meaning,

- 3-do not know,

- 4-no response.

An icon must receive $66 \%$ correct answers to be acceptable, but this is raised to $85 \%$ in a safety critical situation, such as for automation mode (BSI 2014; Zwaga and Mijksenaar 2000; Foster et al. 2010; Arcia, et al. 2019). Where results are poor, analysis of the results can be used to redesign the icon, resulting in an iterative approach (Zwaga and Mijksenaar 2000; Foster et al. 2010).

No literature has assessed the implications of the lack of standardisation, and much inconsistency in icons, related to automated driving. Misinterpretation of the icons relating to automation involves risks, which at their extreme could cause no one to be in control of the vehicle or for a dangerous unnecessary intervention to take place. Therefore, a focus group was held to determine whether these safety critical icons could be recognised and understood by the driving public. A demographically diverse range of participants in terms of age, gender, type of vehicle used, annual mileage and driving experience were recruited. They were asked to interpret the meaning of a variety of displays from the three different manufacturers of SAE level 2 vehicles used in previous studies (Kim et al 2020a, b), an SAE level 3 vehicle, for comparison, and from two high fidelity simulators where studies had previously been conducted (Politis, et al. 2018).

\section{Method}

\subsection{Participants}

Ethical approval was gained via the University of Southampton Ethics and Research Governance Office (ERGO number: 48777). Seven participants were recruited across three age groups; $18-34,35-56$ and $56-80+$ to ensure an inclusive sample meeting the group size (5-10) commonly recommended in the literature (Caplan 1990; Krueger and Casey 2015; Morgan 1997a). Participants were recruited via posters around the university campuses, posts on social media, direct emailing to a list of people who had previously expressed interest in taking part in research undertaken by this team, and to ensure age group 3 was captured, contacting the local branch of 'The University of the Third Age', an organisation who describe themselves as a group 'which brings together people in their 'third age' to develop their interests and continue their learning' (University of the Third Age 2019). These age groups were chosen in order to align with other work within the same project (Clark et al. 2019). Time constraints allowed only a single focus group to be held, which, according to Morgan (1997c), is acceptable as long as the results are interpreted cautiously. Demographic information for the participants is shown in Table 1.

\subsection{Design}

The focus group lasted $2 \mathrm{~h}$, in line with the recommendations of Krueger and Casey (2015) and Morgan (1997b). Demographic information collected included age, gender, annual mileage, years holding a full driving licence, any advanced
Table 1 Participant demographics

\begin{tabular}{llllll}
\hline Participant & Age group & Gender & $\begin{array}{l}\text { Years since pass- } \\
\text { ing test }\end{array}$ & Annual mileage & ADAS score \\
\hline 1 & 2 & M & 25 & 1000 & 4 \\
2 & 1 & F & 6 & 2000 & 3 \\
3 & 1 & F & 13 & 10,000 & 11 \\
4 & 2 & M & 22 & 30,000 & 2 \\
5 & 3 & F & 54 & 10,000 & 2 \\
6 & 3 & M & 56 & 13,000 & 6 \\
7 & 1 & M & 3 & 2000 & 3 \\
\hline
\end{tabular}


driver qualifications (none reported for any participant) and experience in using a range of 17 advanced driver-assistance systems (ADAS). The ADAS categories were carefully worded to represent systems used by all manufacturers and standard explanations were provided for each. Participants were asked to select one of three radio buttons to describe their experience of each ADAS as either, 'no experience', 'I have tried this but I'm not experienced' or 'I regularly use this feature and consider myself an experienced user'.

The event started with an introduction to the subject of the workshop and focus group in line with common practice (Krueger and Casey 2015; Morgan 1997b). The concepts of signs and symbols which are currently commonly displayed on a vehicle dashboard during highly automated driving and automated to manual takeover were explained and then demonstrated using a manufacturer promotional video. The session then commenced and was formed of three exercises which followed the convention of progressing from structured to less structured (Morgan 1997c; Cooper and Baber 2004).

\subsection{Equipment}

Multiple strategies were used for data capture:

- Two Sony HandyCam video cameras were mounted on tripods close to the group in order to obtain footage and audio recording of the group discussions, which was subsequently transcribed.

- A GoPro video camera was mounted high up above the group in order to obtain footage of the group moving and placing the materials on the table.

- Printed copies of icons (compiled in Table 2).

- Workbooks containing images of the icons, accompanied by notes written by the participants, and comments from the group written by the facilitators on flip charts during the exercises.

\subsection{Procedure}

The first exercise was a written task. In this, the participants were presented with a workbook containing images of icons from the aforementioned vehicles and simulators, each with an adjacent area for writing their response. The icons were shown in context within the vehicle, accompanied by an isolated enlarged version shown in Table 2, and they were asked the same four questions for each image.

i. What is the meaning of this icon?

ii. Why is the icon being presented?

iii. What do you like about this icon? iv. What do you dislike about this icon?

These questions were devised in line with the recommendations of Cooper and Baber (2004).

The group was then given some further guidance from the facilitator about the types of messages these icons could be conveying, and the participants were asked to categorise the icons by placing the images under categories placed on the table. These categories were:

i. What the vehicle is sensing.

ii. What automation capability is possible.

iii. What driver actions are required.

iv. What mode the vehicle was in.

The participants then discussed their choices as a group and rearranged the icons on the table until they came to a consensus as to their meaning. The facilitator ensured that all participants were able to engage with the discussions. The event finished with the third exercise, an unstructured session allowing for any comments and recommendations to be made, which were captured by a facilitator on a flip chart.

\subsection{Method of analysis}

The scripts from the written task were categorised by icon and the comments compared; they were sorted into "correct', 'wrong', 'wrong and response is the opposite of the intended meaning' and 'do not know', in line with the ISO 9186 Graphical Symbols Test (BSI 2014). This was repeated with the printed icons from the second task. The audio from videos of the study was transcribed and categorised and sorted in the same manner. For the final task, the flip chart pages were sorted into themes such as colour, standardisation and recommendation.

As colour was of such a concern to the participants, a comparison was undertaken between the interpretations of the meaning of colours from the participants' comments, how these were used in the icons used in the focus group, standards recommended by authors and the recommendations from ISO 2575. The results can be seen in Table 3 .

\section{Results}

\subsection{Exercise one}

\subsubsection{Icons indicating automation mode active}

Each manufacturer, and the simulators, have icons to indicate that the automation system is active. Most of the participants were able to interpret these icons accurately, but 
Table 2 Mode icons used in focus group.

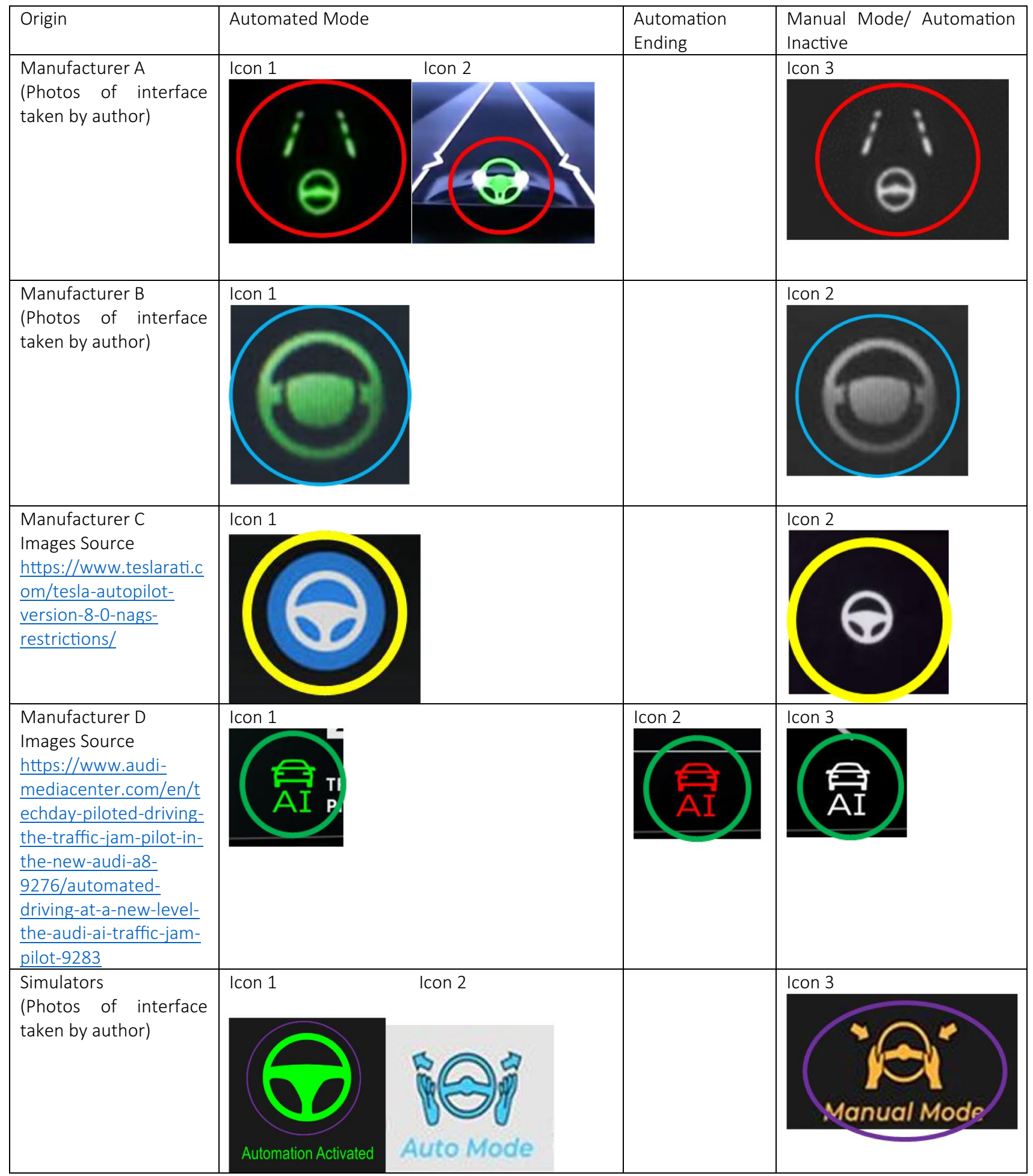

some participants had more unusual opinions: 'the car is driving correctly within the lane' (e.g. Table 2, Manufacturer A, Icon 1), 'pavement is irregular, or narrow roads, slow down'. Some participants expressed confusion: 'unclear', 'is car driving itself?', 'no idea'. One participant interpreted Manufacturer A, Icon 2 to mean the opposite to that intended; 'you are holding the steering wheel, feedback to driver that car recognises they are doing as asked' (Table Manufacturer A, Icon 2). 
Table 3 Comparisons of meanings of colours from, manufacturers, simulators, focus group, ISO and recommendations

\begin{tabular}{|c|c|c|c|c|c|}
\hline Source & Red & Amber/yellow & Green & Blue & White/grey \\
\hline Manufacturer A & - & - & Auto active & - & Auto not active \\
\hline Manufacturer B & - & - & Auto active & - & Auto not active \\
\hline Manufacturer $\mathrm{C}$ & Auto ending imminent & - & - & Auto Active & Auto not active \\
\hline Simulators & & $\begin{array}{l}\text { Manual mode } \\
\text { Auto not active }\end{array}$ & Auto active & Auto Active & - \\
\hline Focus Group & $\begin{array}{l}\text { Not active } \\
\text { Unsafe }\end{array}$ & $\begin{array}{l}\text { Caution } \\
\text { Standby } \\
\text { Normal }\end{array}$ & $\begin{array}{l}\text { Auto active } \\
\text { Safe }\end{array}$ & $\begin{array}{l}\text { Unsure } \\
\text { Ambiguous } \\
\text { Hybrid }\end{array}$ & Ambiguous \\
\hline ISO 2575 & Danger Immediate or imminent & Caution & $\begin{array}{l}\text { Safe } \\
\text { Normal }\end{array}$ & High Beam & $\begin{array}{l}\text { Used when no } \\
\text { other condition } \\
\text { applies }\end{array}$ \\
\hline Green et al. (1995) & $\begin{array}{l}\text { Critical warning } \\
\text { Action required }\end{array}$ & Caution & - & - & - \\
\hline Horton (1994) & Danger & Caution & Safe & Information & - \\
\hline
\end{tabular}

\subsection{Icons indicating manual mode or automation ending/inactive}

All of the manufacturers have icons indicating that the automation is inactive or ending, and the simulator has an icon to indicate manual mode. Some of the more unusual interpretations were as follows: 'indentation in pavement, take care of kerb', 'road narrows, slow down' (e.g. Table 2, Manufacturer A, Icon 1), and 'speed control active', and some were confused: 'Unclear. Could be anything or nothing', 'unsure, maybe AI inactive'. Some participants again made opposing interpretations; 'don't use steering wheel', 'steering is in auto mode for the rest of the journey', 'AI is in control' (e.g. Table 2, Manufacturer C, Icon 2).

\subsubsection{Colour}

There were many comments about the colour of the icons and what the colours meant:

Green (e.g. Table 2, Manufacturer A, Icon 1)_-'I like colour coding' (green meaning active), 'active as it's green', 'the steering wheel is green which is positive confirmation', 'green resonates as something being active'.

Orange/amber (e.g. Table 2, Simulators, Icon 2)—'amber resonates as caution/be alert'.

Red (e.g. Table 2, Manufacturer C, Icon 2)—'could be red to give you a clear on-off indication' (referring to an icon which greys out when inactive).

\subsubsection{Size and text labels}

The participants were able to see the icons in context within the IVIS, and so were able to determine how large they were. There were several comments regarding size: "icon so small on dash', 'it's small', 'very small-easily missed', 'maybe a bit small', 'small, meaning it is unclear', 'icon is quite small in cluster'. Those icons which were accompanied with a text label, e.g. Table 2, Simulators, Icon 1, were more easily understood than those without and it was suggested by one participant that text should be added to those icons which were more ambiguous; however, some participants found the text annoying or too long.

\subsubsection{Exercise two}

The various interpretations were discussed by the group in detail and this revealed some opposing views, e.g. Table 2, Manufacturer A, Icon 2:

Participant A, 'I think if my hands were off the wheel and I saw that, it would be very obvious that I need to put my hands on the wheel'.

Participant B, 'If my hands were on the wheel, I'd take them off the wheel'.

Also, some ambiguity, e.g. Table 2, Manufacturer C, Icon 2:

Participant C, 'I don't know whether it's available or not. I wouldn't be sure if it's available'.

Participant D, 'I'm not sure that it's not available either'.

There were also many discussions regarding the use and meaning of colour. A number of icons used green colouring in the automated mode, while one was blue. Orange and white/grey were used to indicate no automation/ manual mode and one icon used red to indicate the automated mode was ending (see Table 2). The participants again had opinions as to what the colours should represent:

Green-'Because it's green, it's suggesting automated mode', 'Green is automated active', 'So green means safe'.

Orange/Amber-'Kind of a standby thing', 'Orange so it's a caution', 'warning', 'orange means normal'. 
Red-'Not active', 'red means unsafe', 'and red that was not active'.

Blue-'Blue is a big question mark', 'Blue suggests hybrid'.

White-'Not being green or any colours (e.g. greyed out/white) also suggests to me that it's not on an automated mode'.

There was also a discussion around standardisation and how this is helpful in aiding understanding. One participant commented, 'Most things are standardised... like traffic lights. They become standardised... so that everyone ends up having it the same way'.

\subsubsection{Exercise three}

The final task was a less structured, open discussion, but raised some of the same concerns as the previous tasks. The use of colour in icons was still of significance, with participants commenting: 'Consistency of colour across manufacturers is important' and 'colour coding should be consistent-stick to red/orange/ green. Blue and grey are ambiguous'. With further comments around standardisation: 'Don't like icons—need to be standardised' and 'icons should be standardised'.

\subsubsection{ADAS experience}

From the form completed before the study, the lowest score was 2 , and the highest was 11 . As the maximum possible score was 34 , this range of scores indicates that the participants had a low to moderate amount of experience in using ADAS. No participants had experienced driving a highly automated vehicle such as those used in this study (all scores can be seen in Table 1). Those participants with the lowest amount of experience using ADAS were also more likely to interpret the icons incorrectly during both the unguided individual task, and following the extra guidance during the second task, making interpretations such as 'pavement is irregular', or 'narrow roads, slow down' for the first task and 'road narrows, slow down' in the second task. Equally, those with more ADAS experience were more able to identify the icons correctly, even from the initial unguided task.

\section{Discussion}

It can be seen that the majority of icons from the manufacturers and from the simulator, designed to indicate mode, are based on the representation of a steering wheel. One manufacturer has opted to use the image of a car. These icons can be classed as concept-related icons; they are based on an image of an actual object and sometimes an associated action (Carney, Campbell and Mitchell 1998). These are moderately difficult to learn and it is therefore not surprising that some participants found them challenging to interpret without guidance or previous experience. Where participants had made more unusual interpretations of the icons, it can be seen that they were examining them more closely as a pictorial type icon, seeing the image in front of them as a literal representation of the road ahead; these participants also had less ADAS experience. Those with more experience of ADAS were more likely able to identify the modes indicated by the icons correctly. Whilst no participants have these automation capabilities in their own vehicles, it may be possible to hypothesise that those with more ADAS experience were more used to the concept-related icon, and were therefore able to interpret these new icons more easily.

Some participants interpreted icons identifying the automation mode inversely, effectively believing a car was not in automated mode when it was, but more concerning was the understanding that the car was in automated mode when it was not. This ambiguity could cause a driver to omit making driving inputs, causing an accident, resulting in damage to the vehicle and harm to the driver, passengers and other road users. There would also be a negative economic impact to the driver in terms of increased insurance premiums, vehicle repair or replacement, any casualties from medical bills and missed employment, and to society as a whole from emergency services and highway repair (Gorea 2016). In addition, accidents related to an automation system can cause negative media coverage, such as that received by Tesla following a fatal crash in 2016 (NTSB 2020), leading to public distrust in the manufacturer or similar systems and therefore also having a negative economic impact on the original equipment manufacturers.

Colour of icons was important to the participants and was raised by them in all three exercises. Colour can increase the likelihood icons are noticed (Young 1991), and when used well can aid communication. However, when used carelessly, they can increase confusion (Horton 1994). The colours used in the icons during this focus group were as follows: white/grey, green, blue, amber/yellow and red, as seen in Table 2. Participants made many comments about how they interpret the meaning of colours. They referred to the use of colour in IVIS as they experience it in their own vehicles, but also made comparisons to traffic lights.

These meanings of colours stated by the participants were, what they considered, a conventional interpretation. This aligns closely with the meaning attributed to colour in ISO 2575. The use of new colours (white and blue), or colours not meeting their expectation, was deemed confusing by the participants. It is interesting to compare the opinions of the focus group and the ISO standards with that of authors who have written recommendations for the use of colour in icon design from an IT perspective (Horton 1994) and from a human factors perspective (Green 1995). Table 3 shows a 
summary of the colours and actual meanings from the icons used in the focus group, the focus group participants, ISO 2575, and those of the authors of recommendations. From Table 3, it is clear that colour use is inconsistent between the manufacturers and simulators, but they also appear misaligned from the opinions of the focus group. The participants opinions generally match the ISO standards, which they will have experienced in their own vehicles, and with those listed in the recommendations.

It is acknowledged that this paper was limited in its scope by relying on a single focus group, and the participants having low to moderate ADAS experience. However, recommendations for future work could include repeating the exercises with more focus groups and recruiting some participants with higher experience of ADAS, perhaps comparing novice and expert users.

Carney, Campbell and Mitchell (1998), Green (1995) and Zwaga and Mijksenaar (2000) have highlighted the importance of a human factors-led approach to icons in IVIS, and the studies conducted by Green (1979) and Chong, Clauer and Green (1990) had user-led approach to the initial stages of design. After some polishing, these designs could be scored using the ISO 9186 test as part of a human factors and user-led iterative design process.

\section{Conclusion}

Due to a lack of standardisation in the icons relating to automated driving, manufacturers are independently designing icons, causing inconsistency (Carney, Campbell and Mitchell 1998). A focus group was conducted in order to determine if a range of icons, identifying mode in an automated vehicle, could be understood by driving members of the public. During the initial exercise, the participants were asked to write their interpretations and meanings of a number of icons used in semi-autonomous vehicles and simulators. They reported a wide range of ideas about the meaning of the icons. Those participants with more experience of advanced driver-assistance systems (ADAS) in their own vehicles were more likely to have correct or similar ideas as to the meaning of the icons. Those with less experience of ADAS attributed a wider range of ideas related to the way they interpreted the icons, seeming to make more literal interpretations. Before the second exercise, the participants received additional guidance about the possible meanings of the same icons. The participants were able to make a correct interpretation of more icons than in the previous task, suggesting that these could not be considered pictorial or concrete types as some learning was required in order to identify them (Carney, Campbell and Mitchell 1998; Lin 1994; McDougall et al. 2000). However, they were also in agreement that several icons remained ambiguous, suggesting these icons were arbitrary or abstract. The final exercise allowed the participants to openly discuss the icons they had seen. This section showed that colour and standardisation were considered important when trying to understand icons. The participants considered it essential that colours were only used in what they considered the conventional manner; their opinions on the use of colour aligned well with the colour standards outlined in ISO 2575.

The authors acknowledge that due to constraints of the project, the focus group contained a small amount of participants. Future work would benefit from using multiple focus groups with a diverse range of participants including those who had experience of more advanced automation features.

Following these exercises and discussions, it is recommended that ISO standards should be created for the icons used in in-vehicle information systems, indicating automated and manual modes, in order to reduce driver confusion. These icons should be designed using existing human factors methodologies such as using the target population to help develop candidate icons, and tested using the ISO 9186 to ensure they are simple, clear, concise and universally understood.

Acknowledgements The authors acknowledge Simon Thompson at Jaguar Land Rover for his support in preparing this paper.

Funding This work was supported by Jaguar Land Rover and the UKEPSRC grant EP/N011899/1 as part of the jointly funded Towards Autonomy: Smart and Connected Control (TASCC) Programme.

\section{Declarations}

Competing interests The authors declare no competing interests.

Open Access This article is licensed under a Creative Commons Attribution 4.0 International License, which permits use, sharing, adaptation, distribution and reproduction in any medium or format, as long as you give appropriate credit to the original author(s) and the source, provide a link to the Creative Commons licence, and indicate if changes were made. The images or other third party material in this article are included in the article's Creative Commons licence, unless indicated otherwise in a credit line to the material. If material is not included in the article's Creative Commons licence and your intended use is not permitted by statutory regulation or exceeds the permitted use, you will need to obtain permission directly from the copyright holder. To view a copy of this licence, visit http://creativecommons.org/licenses/by/4.0/.

\section{References}

Arcia ALV, Grossman, George M, Turchioe MR, Mangal S, Creber RMM (2019) "Modifications to the ISO 9186 method for testing comprehension of visualizations: successes and lessons learned." 2019 IEEE Workshop on Visual Analytics in Healthcare. Vancouver, Canada: IEEE. 41-47. https://doi.org/10.1109/VAHC47919. 2019.8945036 
Baber C, Wankling J (1992) An experimental comparison of text and symbols for in-car reconfigurable displays. Appl Ergon 23(4):255-262. https://doi.org/10.1016/0003-6870(92)90153-M

BSI (2018) BS ISO 2575. Road vehicles. Symbols for controls, indicators and tell-tales

BSI (2010) BS ISO 2575: Road vehicles - symbols for controls, indicators and tell-tales

BSI (2014) BS ISO 9186-1: 2014, Graphical symbols — Test methods - Part 1: Method for testing comprehensibility

Campbell JL, Brown JL, Graving JS, Richard CM et al (2016) Human factors design guidance for driver-vehicle interfaces (Report No. DOT HS 812 360). Washington DC: National Highway Traffic Safety Administration

Caplan S (1990) Using focus group methodology for ergonomic design. Ergonomics 33(5):527-533. https://doi.org/10.1080/0014013900 8927160

Carney C, Campbell JL, Mitchell EA (1998) In-vehicle display icons and other information elements: literature review. Literature Review, US Department of Transportation

Chanwimalueng W, Rapeepisarn K (2013) A study of the recognitions and preferences on abstract and concrete icon styles on smart phone from Easterners and Westerners' point of view. 2013 International Conference on Machine Learning and Cybernetics. Tianjin, China: IEEE. 1613-1619. https://doi.org/10.1109/ ICMLC.2013.6890858.

Chong M, Clauer T, Green P (1990) Development of candidate symbols for automobile functions. Technical Report, The University of Michigan Transportation Research Institute

Clark JR, Stanton NA, Revell K (2019) Directability, eye-gaze, and the usage of visual displays during an automated vehicle handover task. Transport Res f: Traffic Psychol Behav 67:29-42. https:// doi.org/10.1016/j.trf.2019.10.005

Cooper L, Baber C (2004) Focus Groups. In Handbook of Human Factors and Ergonomics Methods, by N. A. Stanton, A. Hedge, K. Brookhuis, E. Salas and H. Hendrick, 321-328. CRC Press

Department for Transport (2018) Reported road casualties in Great Britain: quarterly provisional estimates year ending June 2018. 8 November. Accessed October 1, 2019. https://assets.publishing. service.gov.uk/government/uploads/system/uploads/attachment_ data/file/754685/quarterly-estimates-april-to-june-2018.pdf.

Foster JJ, Koyama K, Adams A (2010) Paper and on-line testing of graphical access symbols in three countries using the ISO 9186 comprehension test. Information Design Journal 18(2):107-117. https://doi.org/10.1075/idj.18.2.02fos

Frank D, Koenig N, Lendholt R (1973) Identification of symbols for motor vehicle controls. SAE Transactions, 82:2153-2161. www. jstor.org/stable/44717612. Accessed 18 June 2020

Gasser TM, Westhoff D (2012) BASt-study: definitions of Automation and Legal Issues in Germany. 25 July.

Gorea R (2016) Financial impact of road traffic accidents on the society. International Journal of Ethics Trauma \& Victimology 2(1):6-9. https://doi.org/10.18099/ijetv.v2i1.11129

Green P (1993) Design and evaluation of symbols for automobile controls and displays. In Automotive Ergonomics, by B. Peacock and W. Karwowski, 237-268. Washington DC, US: Taylor \& Francis.

Green P (1979) Development of pictographic symbols for vehicle controls and displays. 1979 Automotive Engineering Congress and Exposition. SAE International. https://doi.org/10.4271/790383.

Green P (1981) Displays for automotive instrument panels: production and rating symbols. HSRI Research Review 12(1):1-12

Green P (1995) Measures and methods used to assess the safety and usability of driver information systems. Technical Report FHWARD-94-088, McLean, US: Federal Highway Administration.

Greenberg G (2013) Beyond Resemblance. Philos Rev 122(2):215287. https://doi.org/10.1215/00318108-1963716
Goonerilleke RS, Shih HM, On HK, Fritsch J (2001) Effects of training and representational characteristics in icon design. Int J Hum Comput Stud 55:741-760

Harvey C, Stanton NA (2013) Usability evaluation for in-vehicle systems. CRC Press, London, UK

Horton WK (1994) The icon book: visual symbols for computer systems and documentation. John Wiley \& Sons Inc, New York, US

ISO (2014) Economic Benefits of Standards.

ISO (2016) ISO 17488:2016, Road vehicles - transport information and control systems - detection-response task (DRT) for assessing attentional effects of cognitive load in driving

ISO (2010) ISO 2575:2010, Road vehicles - Symbols for controls, indicators and tell-tales

ISO (2017) ISO 2575:2010/AMD 7:2017, Road vehicles — symbols for controls, indicators and tell-tales - Amendment 7

ISO (2013) The International Language of ISO Graphical Symbols.

Kim J, Revell K, Langdon P, Bradley M, Politis I, Thompson S, Skrypchuk L, et al. 2020. "Drivers' interaction with, and perception toward semi-autonomous vehicles in naturalistic settings." International Conference on Intelligent Human Systems Integration. Advances in Intelligent Systems and Computing. Cham, Switzerland: Springer. 20-26. https://doi.org/10.1007/ 978-3-030-39512-4_4.

Kim J, Revell, Langdon P, Bradley M, Politis I, Thompson S, Skrypchuk L, et al (2020)Semi-automated driving has higher worload and is less acceptable to drivers than manual vehicles in "designing interaction and interfaces for automated vehicles" Stanton. $\mathrm{N}$. A., Revell, K. M. A. and Langdon, P. (Eds) CRC Press

Krueger RA, Casey MA (2015) Focus groups: a practical guide for applied research. Sage Publications, Thousand Oaks, US

Khan T, Pitts M, Williams MA (2016) Cross-cultural differences in automotive HMI design: a comparative study between UK and Indian users' design preferences. J Usability Stud 11(2):45-65

Lin R (1994) A study of visual features for icon design. Des Stud 15(2):185-197. https://doi.org/10.1016/0142-694X(94)90024-8

Locken A, Sadeghian S, Muller H, Gable TM et al (2000) Towards adaptive ambient in-vehicles displays and interactions: insights and design guidelines from the 2015 automative UI dedicated workshop In Automotive User Interfaces - Creating Interactive Experiences in the Car Meixner, G. \& Muller, C. (Eds) Springer

McDougall SJP, de Brujin O, Curry MB (2000) Exploring the effects of icon characteristics on user performance: the role of icon concreteness, complexity, and distinctiveness. J Exp Psychol Appl 6(4):291-306. https://doi.org/10.1037/1076-898X.6.4.291

Meixner G, Hacker H, Decker B, Gerlach S, Hess A et al (2000) Retrospective and future automotive infotainment systems - 100 years of user interface evolution In Automotive User Interfaces - Creating Interactive Experiences in the Car Meixner, G. \& Muller, C. (Eds) Springer

Morgan DL (1997a) Focus groups as qualitative research (2nd ed.). Sage Publications. https://doi.org/10.4135/9781412984287.

Morgan DL (1997c). Planning Focus Groups. Sage Publications.

Morgan DL (1997b) The Focus Group Guidebook. Sage Publications.

Moser S (1998) Ancestral Images: The Iconography of Human Origins. Sutton Publishing Limited, Stroud, UK

NTSB (2020) NTSB Opens Public Docket for 2 Ongoing Tesla Crash Investigations. 11 February. https://www.ntsb.gov/news/pressreleases/Pages/NR20200211.aspx.

Politis I, Langdon P, Adebayo D, Bradley M, Clarkson PJ, Skrypchuk L, Mouzakitis A, et al (2018) An Evaluation of Inclusive Dialogue-Based Interfaces for the Takeover of Control in Autonomous Cars. Proceedings of the 2018 Conference on Human Information Interaction \& Retrieval - IUI'18: 23rd International Conference on Intelligent User Interfaces. Tokyo, Japan: ACM Press. 601-606. https://doi.org/10.1145/3172944.3172990. 
Priest HA, Wilson KA, Salas E (2005) National standardization efforts in ergonomics and human factors. In Handbook of Standards and Guidelines in Ergonomics and Human Factors, by W. Karwowski, https://doi.org/10.1201/9781482289671. Boca Raton, US: CRC Press.

Revell K, Richardson J, Langdon P, Bradley M, Politis I, Thompson S, Skrypchuk L et al (2018) “"'That was scary...” exploring driver-autonomous vehicle interaction using the Perceptual Cycle Model." Contemporary Ergonomics and Human Factors.

SAE (2018) Taxonomy and Definitions for Terms Related to Driving Automation Systems for On-Road Motor Vehicles J3016_201806 Accessed $1^{\text {st }}$ February 2020. https://www.sae.org/standards/conte nt/j3016_201806/

CS Saunby EI Farber J DeMello 1988 Driver Understanding and Recognition of Automotive ISO Symbols Technical Paper 880056 https://doi.org/10.4271/880056,SAEInternational

Shen, Z., Xue, C. and Wang, H. 2018 'Effects of Users' Familiarity With the Objects Depicted in Icons on the Cognitive Performance of Icon Identification” i-Perception 9(3) 1-17. https://doi.org/10. $1177 / 2041669518780807$

Sherehiy, B., W. Karwowski, and D. Rodrick. 2006. "Human Factors and Ergonomics Standards." In Handbook of Human Factors and Ergonomics, by G. Salvendy. John Wiley \& Sons, Inc.

Stanton NA, Dunoyer A, Leatherland A (2011) Detection of new inpath targets by drivers using Stop \& Go Adaptive Cruise Control. Appl Ergon 42(4):592-601. https://doi.org/10.1016/j.apergo.2010. 08.016

Stuart-Buttle, C. 2006. "Overview of National and International Standards and Guidelines." In Handbook of Standards and Guidelines in Ergonomics and Human Factors, by W. Karwowski. Boca Raton, US: CRC Press.

Su Y (2018) App Interface Icon Design Based on Information Theory. Advances in Social Science and Humanities Research 283:471-476
University of the Third Age. 2019. About the U3A. Accessed September 16, 2019. https://www.u3a.org.uk/about.

Walch, M., Muhl. K., Kraus. J., Stoll, T., et al "From car-driver-handovers to cooperative interfaces: visions for driver-vehicle interaction in automated driving" In Automotive User Interfaces - Creating Interactive Experiences in the Car Meixner, G. \& Muller, C. (Eds) Springer

Walker, G. H., Stanton, N. A. and Salmon, P. 2017 "Human Factors in Automotive Engineering and Technology" CRC Press

World Health Organization. 2018. Global status report on road safety 2018. Accessed February 26, 2020. https://www.who.int/viole nce_injury_prevention/road_safety_status/2018/en/.

You, F., Yang, Y., Fu, M., Wang, J., et al "Icon Design Recommendations for Central Consoles of Intelligent Vehicles" In "Human Interaction, Emerging Technologies and Future Applications II" https://doi.org/10.1007/978-3-030-44267-5_43

Young SL (1991) Increasing the noticeability of warnings: effects of pictorial, color, signal icon and border. Proceedings of the Human Factors and Ergonomics Society Annual Meeting 35(9):580-584. https://doi.org/10.1518/107118191786754662

Zwaga HJ, Mijksenaar P (2000) the development and standardization of warning symbols; the role of design and human factors. Proceedings of the Human Factors and Ergonomics Society Annual Meeting 44(28):782-785. https://doi.org/10.1177/1541931200 044028104

Publisher's note Springer Nature remains neutral with regard to jurisdictional claims in published maps and institutional affiliations. 